\title{
A GUERRA DE SEXOS EN LAS COMEDIAS ROMÁNTICAS DE HOWARD HAWKS: LA FIERA DE MI NIÑA (BRINGING UP BABY, 1938), LUNA NUEVA (HIS GIRL FRIDAY, 1940), LA NOVIA ERA ÉL (I WAS A MALE WAR BRIDE, 1949), Y SU JUEGO FAVORITO (MAN'S FAVORITE SPORT, 1964)
}

\author{
BEGOÑA MONTESINOS LADRÓN DE GUEVARA
}

Investigadora independiente begohistoria2@hotmail.com

\begin{abstract}
Resumen: Howard Hawks plantea el enfrentamiento entre los sexos en buena parte de su filmografía. Comedias románticas, western o cine de aventuras comparten esta guerra de sexos que se inicia con una antipatía mutua entre los protagonistas que va evolucionando a medida que la pareja se ve inmersa en sus aventuras para transformarse en amistad, atracción, y finalmente amor. Cuatro de sus comedias La fiera de mi niña (Bringing Up Baby, 1938), Luna nueva (His Girl Friday, 1940), La novia era él (I was a Male War Bride, 1949) y Su juego favorito (Man's Favorite Sport,1964) plantean la guerra de sexos a través de una inversión de los roles sexuales; mujer-activo / varón-pasivo que finalmente revierte a modelos más tradicionales.
\end{abstract}

Palabras clave: Howard Hawks / comedia romántica / guerra de sexos / inversión de roles / masculino / femenino.

BATTLE OF SEXES ON HOWARD HAWKS'S ROMANTIC COMEDIES: BRINGING UP BABY

(1938), HIS GIRL FRIDAY (1940), I WAS A MALE WAR BRIDE (1949), AND MAN'S FAVORITE

SPORT (1964)

Abstract: Howard Hawks raises the confrontation between the sexes in much of his filmography. Romantic comedies, western or adventure movies share this battle of the sexes that begins with a mutual antipathy between the protagonists that evolves as the couple is immersed in their adventures to become friendship, attraction, and finally love. Four of his comedies Bringing Up Baby (1938), His Girl Friday (1940), I was a Male War Bride (1949) and Man's Favorite Sport (1964) propose the battle of the sexes through a sex roles reversal; womanactive / male-passive that finally reverts to more traditional models.

Key words: Howard Hawks / romantic comedy / battle of sexes / roles reversal / male / female.

\section{Introducción}

La guerra de los sexos es un tema recurrente que desde hace décadas sustenta los argumentos de las comedias románticas, desarrollando las diferencias entre hombres y mujeres y expresando for- mas de comportamiento distintas en las relaciones entre ellos.

El antagonismo inicial y las disputas entre los protagonistas nutren estos argumentos generando conflictos que están destinados a causar situaciones có-

* Fecha de recepción: 15 de abril de 2019 / Fecha de aceptación: 23 de abril de 2020. 
micas que se terminan por resolver de modo feliz, aunque un análisis más específico permita ver cómo las discusiones en el seno de la pareja dan lugar al dolor con agresiones físicas y verbales, si bien el espacio de la comedia tamiza el impacto del mismo.

Esta fórmula amor-odio suele manifestarse con una hostilidad creciente entre la pareja. Tradicionalmente se ha relacionado la incompatibilidad inicial entre la pareja como una forma de reafirmar la compatibilidad final entre ellos, esto explica la atracción que siente el espectador ante la continua representación intermedia de esta hostilidad. En estas comedias, tal y como expone Molly Haskell el amor no sustituye a la fricción, sino que se expresa a través de ella: "Un hombre y una mujer se provocan y florecen en contacto con el otro, se rozan continuamente $y$, en medio de esta fricción, a la luz mutua de sus ojos, parecen descubrirse por primera vez".

Howard Hawks, plantea este enfrentamiento entre los sexos en buena parte de su obra cinematográfica. ${ }^{2}$ Destacamos aquí su producción dentro del género de la comedia romántica. Un espacio que se ha constituido como un lugar privilegiado para la articulación de discursos sobre las relaciones heterosexuales, y sobre el rol de las identidades masculina y femenina. Asentado como uno de los principales géneros del cine hollywoodiense, la comedia romántica a pesar de su popularidad, éxito de taquilla y resistencia a lo largo de los años, ha sido denigrada por un sector del público y la crítica, que la consideran como un "género menor": películas de mujeres y para mujeres plagadas de frivolidad, pero son un retrato importante de usos y costumbres que exploran las relaciones heterosexuales.

Centrándonos en estas comedias románticas, cuatro son las que cuentan en su argumento con esta peculiar batalla entre hombres y mujeres: La fiera de mi niña (Bringing Up Baby, 1938), Luna Nueva (His Girl Friday, 1940), La novia era él (I Was a Male War Bride, 1949) y Su juego favorito (Man's Favorite Sport, 1964).
Este corpus de películas comparte unos rituales de seducción donde se manifiestan tanto mecanismos de oposición como de una complementariedad profunda, conseguida a través de la intimidad, la educación mutua, la diversión y el juego. Tal y como apuntan Neale y Krutnik, uno de los pilares fundamentales en la construcción de las tramas de las comedias románticas es el equilibrio entre los aspectos que subrayan la compatibilidad esencial de la pareja con los obstáculos que impiden temporalmente su mutuo reconocimiento, como pueden ser determinadas manifestaciones de hostilidad entre ellos que en numerosas ocasiones se deben a la falta de un conocimiento necesario para que uno juzgue adecuadamente al otro o a la incapacidad, de uno de los dos, para comprender la situación en la que ambos se ven envueltos. Dificultades que deleitan al espectador que, desde la distancia, sabe que al final los obstáculos serán superados y que la pareja podrá unirse o reunirse, según se trate de una trama de noviazgo o de renovación matrimonial. ${ }^{3}$

Hawks parte de la comedia como el instrumento ideal para crear un cúmulo de situaciones a veces inverosímiles, pero siempre reales; donde los encuentros y las acciones se producen bajo circunstancias casuales que las convierten en mucho más divertidas, aunque una segunda lectura nos revela que sus protagonistas atraviesan situaciones realmente dramáticas, pero narradas de un modo alegre y distendido. ${ }^{4}$

\section{La inversión de roles en las comedias románticas de Hawks}

El cine de Howard Hawks en general, y sus comedias en particular, cuentan con numerosos ejemplos de mujeres que se convierten, como señala Fernández, en "fuente de problemas" para los hombres. ${ }^{5}$ Los protagonistas masculinos de estos filmes, suelen desenvolverse en un universo personal ordenado, donde cada cosa ocupa su lugar y el orden establecido es el que rige sus existencias. Una vida imperturbable que responde a los esquemas que ellos

\footnotetext{
1 "A man and a woman seem to prickle and blossom at each other's touch, seem to rub each other with and against the grain simultaneously, and, in the friction, in the light in the other's eyes, to know themselves for the first time". HASKELL, Molly, 1987, p. 140.

2 La ciudad sin ley (Barbary Coast, 1935), Tener o no tener (To Have and Have Not, 1944) o Rio Bravo (1959), comparten esta guerra de sexos que se inicia con una antipatía mutua entre los protagonistas que va evolucionando a medida que la pareja se ve inmersa en sus aventuras para transformarse en amistad, atracción, y finalmente amor.

${ }^{3}$ NEALE, Steve; KRUTNIK, Frank, 1990, p. 141-143.

${ }^{4}$ Una de las virtudes de estas comedias es la capacidad para hacer posible lo imposible, para construir una lógica del relato que es tan disparatada como los propios personajes y sin embargo es asumida de la forma más natural por el espectador que no puede sino dejarse arrastrar por unos acontecimientos en deuda constante con el azar o el destino.

${ }^{5}$ FERNÁNDEZ, Tomás, 2013, p. 43.
} 
mismos han establecido, pero inevitablemente, esta vida relativamente tranquila, se trastoca ante una situación excepcional, producida por la aparición del elemento femenino, que altera su existencia obligándoles a reubicarse, a avanzar ante nuevas situaciones que les hacen crecer interiormente.

Estas comedias estructuradas en base a la dualidad hombre-pasivo y mujer-activo, descansan sobre la base de la pareja como eje central, donde el protagonista suele ser un hombre muy tímido, con poca experiencia, y perseguido por una mujer resuelta y agresiva. Estos dos universos contradictorios los personaliza en la dualidad hombre-mujer y de su contraste nace una oposición que los conducirá hacia la guerra de sexos.

Sin abandonar el tono desenfadado propio de la comedia, la figura femenina será la que consiga situar al hombre en situaciones verdaderamente descabelladas, impensables e, incluso peligrosas, para conseguir, finalmente, reducir y dominar al varón. ${ }^{6}$ Será ella quien tome la iniciativa, invada el espacio del hombre y logre conquistarlo a pesar de su resistencia inicial. Es la mujer la que tiene el control de la situación, mientras que el hombre es el individuo confuso que avanza sin rumbo hasta que acepta su atracción por ella, siendo la unión de la pareja, la que viene a consolidar esta madurez a la que el héroe se resiste. ${ }^{7}$

Hawks prefiere que sea la chica la que ataque, seduzca y lleve la iniciativa de perseguir y cazar al hombre, según sus propias palabras, considera mucho más interesante este tipo de relación:

Se me ha acusado de promover el movimiento de liberación femenina, y lo he negado tajantemente. Solo da la casualidad de que me resulta atractivo ese tipo de mujer. Simplemente estoy haciendo algo que me gusta. $Y$ he visto tantas películas en las que el héroe sale a la luz de la luna y le dice estupideces a una chica, que le he dado la vuelta, dejando que sea la chica la que haga la conquista, ¿sabe?, y funciona muy bien. En cualquier caso, me sale mejor eso que lo otro. Prefiero con mucho trabajar con un personaje así que con una violeta puritana. ${ }^{8}$

Un análisis detallado de estos filmes nos permite afirmar que la aparición del elemento femenino, como lo denomina Perales, supone un punto de inflexión argumental que afecta a las relaciones personales, laborales y familiares de los protagonistas. Su influencia en el universo masculino es tan importante que los comportamientos masculinos se verán modificados sustancialmente por los impulsos que la mujer provoca en ellos. Únicamente cuando surge la química entre el hombre y la mujer será cuando se reanimen los motores del crecimiento individual, originando un cambio de vida tan drástico que de él se sorprenderá hasta el propio individuo. ${ }^{9}$

La agresividad femenina se manifiesta plenamente en La fiera de mi niña, Luna Nueva, La novia era él y Su juego favorito, en las que se invierten los términos y es la mujer la que domina la situación, convirtiéndose en un peligro para el protagonista, que siente invadido su territorio, y lo sitúa en una posición embarazosa.

Un tanto ambivalente en este aspecto, por su evolución a lo largo del filme, será el personaje de Hildy Johnson (Rosalind Rusell) en Luna nueva. Hildy, reportera de un periódico de gran tirada, es la protagonista más independiente de toda la filmografía de Hawks. Se muestra resuelta y precisa, no necesita apoyarse en el mundo masculino (ella no es la mujer del grupo de periodistas, sino "uno" más de ellos) y su enfrentamiento con sus compañeros periodistas es tan resolutivo como el que mantiene con su jefe y exmarido, Walter (Cary Grant), convirtiéndose así en la réplica perfecta para un protagonista arrogante, dominante y manipulador como él. ${ }^{10}$ Aunque si al principio del fil-

\footnotetext{
6 PERALES, Francisco, 2005, p. 39-40.

7 A propósito de las mujeres en la obra de Hawks, Haskell apunta que se encuentran más cómodas y resultan más atractivas "estando en acción" que posando o luciendo modelos. No son mujeres sumisas: tienen sus propias opiniones y la firme determinación de conseguir sus propósitos. Son mujeres activas, hacen gala de su libertad y son capaces de llevar la iniciativa de las situaciones con su inteligencia y astucia. La coquetería es sustituida por la inmediatez, por una conducta más directa y cercana hacia los hombres. La palabra es su aliado; expresa su inteligencia, pero también la confianza y el dominio que tienen de sí mismas. HASKELL, Molly, 1987, pp. 138-139.

8 "I've been accused of promoting Women's Lib, and I've denied it, emphatically. It just happens that kind of woman is attractive to me. I merely am doing somebody that I like. And l've seen so many pictures where the hero gets in the moonlight and says silly things to a girl, l'd reverse it and let the girl do the chasing around, you know, and it works out pretty well. Anyway, I know that a little better than I do that other stuff. I'd much rare work with a character like that than with some little Puritan violet". McBRIDE, Joseph, 1982, p. 96.

9 PERALES, Francisco, 2005, p. 68-77.

10 En estas batallas, Hawks, juega de forma magistral con los diálogos y la ironía a los que se suma esa forma característica de recitarlos, a toda velocidad, con un ritmo tan vertiginoso, que exige toda la atención posible para no perder ningún matiz. Las situaciones cómicas basadas en acciones verbales están muy presentes en estos filmes, evitando siempre el recurso gratuito
} 


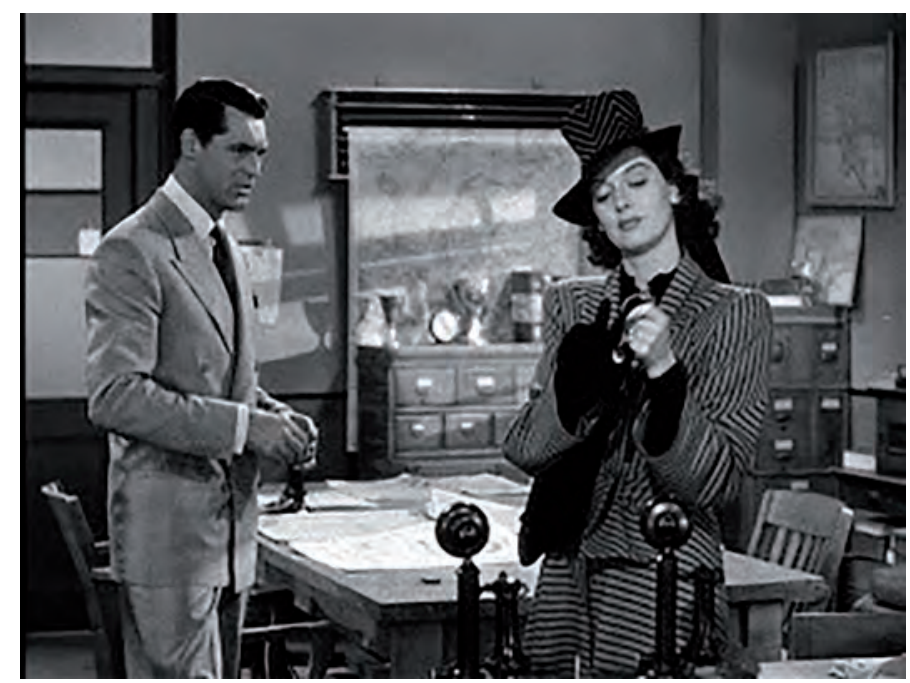

Fig. 1. Fotograma de la película Luna Nueva.

me su comportamiento es el de una mujer liberal acostumbrada a desenvolverse en un mundo dominado por hombres, irá perdiendo su independencia a medida que Walter se adueña progresivamente de la situación.

Hawks subraya la compatibilidad esencial de la pareja formada por Hildy y Walter sobre el espejo cómico de un pretendiente inadecuado que ilustra por contraste todo aquello que en estas comedias resulta imperdonable en un hombre o en una mujer: El indeciso prometido de Hildy, Bruce, interpretado por Ralph Bellamy, subraya la superioridad de Walter, un recurso que utiliza Hawks para convencer al espectador de la conveniencia de la reconciliación entre Walter y Hildy, a pesar de los conflictos entre ambos que les ha llevado a divorciarse. ${ }^{11}$

Si el personaje de Hildy se muestra un tanto ambiguo, el de la teniente Gates ${ }^{12}$ (Ann Sheridan) en La novia era él refuerza la idea de mujer decidida y emprendedora. Catherine Gates representa a la mujer americana moderna e independiente que sabe valerse por sí misma en un ámbito eminentemente masculino como es el militar. En este filme, Hawks recurre al intercambio de los roles sexuales, creando todo un glosario de humillaciones para el capitán Henri Rochard (Cary Grant). Desde el inicio de la película, la seguridad, física y emocional, del capitán se ve puesta en peligro por el marcado carácter hostil de su relación con la teniente Gates, con la que se ve obligado a realizar un largo, accidentado y bochornoso viaje en sidecar por la Alemania de la posguerra. Este peculiar viaje culminará con el matrimonio de la pareja, que tendrá que enfrentarse a las rígidas y absurdas normas burocráticas del ejército americano que impedirán la consumación del matrimonio y convertirán al capitán en female war bride, siendo esta la única posibilidad de la pareja para poder embarcarse en un trasatlántico rumbo a América.

Observamos que las mujeres son también los motores que producen la inversión sexual de los personajes con la consiguiente humillación del varón y su pérdida de control sobre la situación. Intercambiar los roles hombre-mujer es con toda seguridad la inversión que mejor explica este proceso. No tenemos más que hacer un breve repaso a la obra de Hawks para ver cómo se repite este fenómeno. Hildy lleva ropa masculina y su comportamiento con sus compañeros de profesión, exmarido e incluso con su prometido, es rudo, no exento de cierta agresividad; la teniente Gates lleva uniforme y conduce el sidecar con Henri como copiloto. ${ }^{13}$ En el lado opuesto, el hombre se ve obligado a lucir prendas femeninas cuyo caso más relevante, sin duda alguna, tiene lugar en La novia era él, cuando Henri tiene que travestirse de la esposa de un oficial norteamericano para poder embarcar con destino a Estados Unidos. ${ }^{14}$ Este cambio de roles en las comedias opera una con la clara intenciona-

de los chistes o frases graciosas "No recuerdo haber usado jamás una frase graciosa en una película. Resultan graciosas por sus actitudes, por las actitudes que indican lo contrario de lo que tratan de decir" ("I can't remember ever using a funny line in a picture. They become funny because of their attitudes, because of the attitudes that work against what they're trying to say"). McBRIDE, Joseph, 1982, p. 67-68.

${ }^{11}$ El espectador percibe antes que el personaje lo inadecuado del pretendiente con el que aspira a casarse. Un recurso elemental para conseguir este propósito consiste en centrar la narración sobre los dos protagonistas "correctos" y reducir al mínimo las intervenciones del pretendiente, en las cuales su imagen no suele quedar bien parada.

12 PERALES, Francisco, 2005, p. 74.

13 Una de las características principales de las protagonistas será su tenacidad y firmeza, son ellas las que toman la iniciativa y no tienen miedo al compromiso. A pesar de este comportamiento, fuerte e independiente, aparentemente reservado a los hombres, las heroínas de estas películas jamás dejarán de ser intensamente femeninas, por muy masculino que sea su comportamiento o su vestuario.

${ }^{14}$ Los hombres se visten con prendas de mujer en La fiera de mi niña, La novia era él, Me siento rejuvenecer (Monkey Business, 1952) y en Los caballeros las prefieren rubias (Gentlemen Prefer Blondes, 1953). 
lidad; la humillación del hombre con respecto a la mujer. Wood especifica que debe establecerse una distinción entre hombres y mujeres, ya que por lo general resulta divertido que el hombre se vista de mujer, pero para las mujeres, esta práctica de travestismo adopta otro tipo de connotaciones, para ellas es atractivo y favorecedor ${ }^{15} \mathrm{y}$, aportamos, un signo de autoridad que le otorga dignidad.

Pero el intercambio de roles en el que la mujer acosa al hombre va más allá del simple transformismo. El director los ubica en situaciones y equívocos que les ayudarán a extraer de sus experiencias consecuencias constructivas que contribuyan a su crecimiento emocional. Para Francisco Perales la comedia hawksiana proviene de un proceso de inversión de los valores de su protagonista, un protagonista que cree desear algo con fervor, hasta que la aparición de la mujer rompe los esquemas y hace que varíe su comportamiento diametralmente, invirtiendo sus prioridades. ${ }^{16}$

\section{La fiera de mi niña: El modelo a seguir}

Pero sin duda, el culmen en lo que se refiere a la presentación de la mujer como "fuente de problemas" para el hombre lo encontramos en La fiera de mi niña. ${ }^{17}$ En este sentido, Susan Vance ${ }^{18}$ (Katharine Hepburn) supera a todas las anteriores en lo que a generadora de complicaciones para David Huxley (Cary Grant) ${ }^{19}$ se refiere; es capaz de desmontar en unas horas la establecida existencia de un hombre

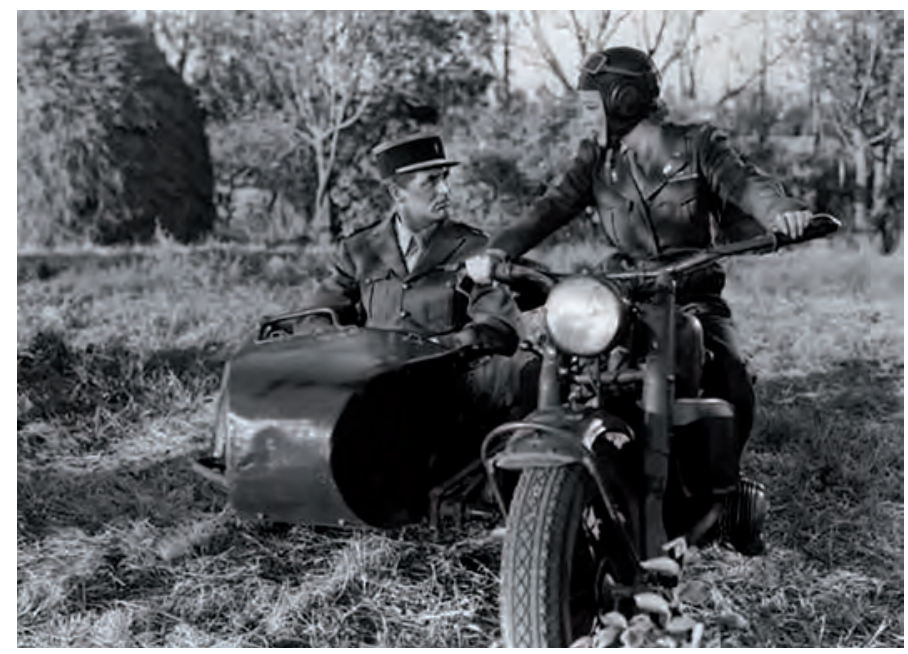

Fig. 2. Fotograma de la película La novia era él.

normal, humillarle progresivamente con las más disparatadas situaciones, despojarlo de su identidad, hacerle olvidar a su prometida y manipularlo a su antojo como si todo hubiera ocurrido casualmente, sin su intervención. ${ }^{20}$

El caos que provocará Susan, ${ }^{21}$ revertirá en una serie de manifestaciones que se traducirán en un proceso de inversión en David, que le permitirá aflorar

15 WOOD, Robin, 2006, p. 184.

16 PERALES, Francisco, 2005, p.113.

17 Una de las piezas más representativas de la comedia screwball y más elogiadas de la historia del cine. En toda lista, antología, clasificación o selección de películas, aparece La fiera de mi niña como una de las mejores comedias de la historia, y una de las mejores películas por extensión. La National Society of Film Critics incluyó La Fiera de mi niña entre las 100 películas esenciales de la historia del cine. CARR, Jay, 2002, p. 48.

${ }_{18}$ Susan representa el paradigma de la mujer hawksiana: atractiva, alta, delgada, inteligente, valiente, descarada, entrometida e independiente. Presenta una imagen inimitable que combina la elegancia con la excentricidad, de acuerdo con su forma de ser. Toda la película está realizada de la misma manera: siempre veremos a Susan con vestidos vaporosos, alegres e incluso disparatados con sombreros increíbles y el pelo suelto. También la veremos siempre en movimiento y muchas veces corriendo de un lado para otro, todo dinamismo y decisión.

${ }^{19}$ La Fiera de mi Niña sería la primera de las cinco películas del tándem Grant-Hawks, el director pensaba que Grant era el actor mejor dotado para la comedia: "Es bastante difícil pensar en otro que no sea Cary Grant para este tipo de cosas. Es hasta tal punto el mejor que no hay nadie que se le pueda comparar" ("It's pretty hard to think of anybody but Cary Grant in that type of stuff. He was so far the best that there isn't anybody to be compared to him"). McBRIDE, Joseph, 1982, p. 69.

20 Las tramas de las comedias románticas, en general, presentan una noción más débil de la realidad que permiten los sucesos más inesperados y sorprendentes sustituyendo la causalidad por la coincidencia, o debilitando la primera mediante estrategias narrativas como el deux ex machina. A pesar de estas posibilidades, el esquema general de las tramas de la comedia romántica sigue descansando en la sucesión de los acontecimientos por un vínculo de causa-efecto.

${ }^{21}$ Aunque el carácter irresponsable e impulsivo de Susan en La fiera de mi niña es la principal "fuente de problemas del relato", no es menos cierto que el resto de personajes femeninos del filme contribuyen a convertirlo en el gran caos que acaba siendo. Es el caso de la tía Elizabeth, que es tan capaz como su sobrina de generar el caos y la confusión, bajo su apariencia de seriedad y severidad; solo hay que ver cómo domina al mayor Applegate; al igual que hace Susan con David, a ratos la tía Elizabeth tampoco le deja ni hablar. También lo es Alice, la prometida de David, quien tampoco le deja hablar: en la primera secuencia, y a tan solo un día de su boda, Alice le deja bien claro a David que las "obligaciones conyugales" no le apartaran ni un milímetro de su trabajo, y que ni siquiera van a disfrutar de una luna de miel. Hasta la señora Gogarty contribuye al caos 


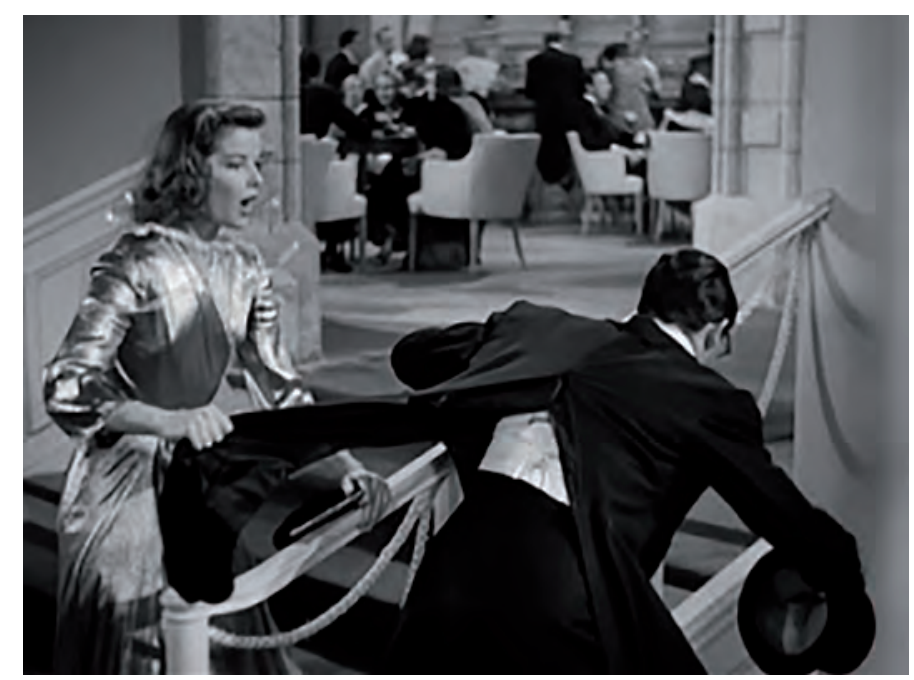

Fig. 3. Fotograma de la película La fiera de mi niña.

actitudes reprimidas que no se atrevía a manifestar. Sometido por una sociedad rígida y represiva que le ha enseñado a no expresarse; serán los efectos turbadores del caos provocado por Susan los que le permitirán liberarse, expandirse y convertirse en el hombre que siempre quiso ser, en un proceso, tratado con un inteligente sentido del humor, que llevará a la total liberación del individuo. ${ }^{22}$

En La fiera de mi niña, Hawks integra y contrapone dos universos distintos: el mundo del saber y la mo- ralidad establecida (él) frente al mundo de la libertad y la irresponsabilidad (ella). Este choque de opuestos desatará una serie de caóticos acontecimientos que mantendrán el pulso cómico a lo largo de toda la historia. Ella, más resuelta y agresiva, será la que tome la iniciativa. Con todo tipo de artimañas conseguirá manipular al indefenso David para mantenerlo junto a ella y conquistarlo a pesar de su resistencia. Esta agresividad femenina será la que consiga situar a su oponente en situaciones disparatadas e irracionales para finalmente reducirlo y dominarlo con el fin de lograr su objetivo: "cazarlo". 23

La intromisión de Susan en la vida del tímido científico lo colocará en tal tesitura que conseguirá derribar su cuadriculado mundo. El tema fundamental que aborda La fiera de mi niña es el de la guerra de sexos, pero el mensaje es mucho más profundo, ya que la verdadera guerra a la que asistimos es la disputada entre los sentimientos y la razón. La ordenada vida que David parece llevar, el dinosaurio que cree constituye la cumbre de su carrera, en realidad no es más que una prisión que necesita derrumbarse para comenzar de nuevo, como él mismo confiesa con una alegría no exenta de cierta pesadumbre hacia el final del filme. ${ }^{24}$

Lo cierto es que, La fiera de mi niña, presenta una cierta ambigüedad al abordar la guerra de los sexos, pues es notorio que la misoginia ${ }^{25}$ a la que habitualmente se ha asociado el cine de Hawks es de doble filo; por un lado, es cierto que asistimos a la dominación del varón por la mujer; parte de la

reinante afirmando por teléfono al comisario Slocum que su señora está en casa descansando, cuando en realidad se encuentra detenida en comisaría junto al resto de personajes. El sexo débil es el masculino en La fiera de mi niña. Y no solo por la clara contraposición entre David y Susan; el resto de los hombres son igualmente débiles, ridículos o insignificantes. El comandante Applegate se las da de valiente cazador, pero no distingue a un león de un leopardo, se asusta y quiere entrar en la casa en cuanto ve a Baby, le dispara sin éxito y en la comisaría pierde la conciencia, y la masculinidad, balbuceando: "Soy la sobrina... la tía. Soy el comandante Horacio Applegate". Al doctor Lehman se le entretiene con una aceituna y es incapaz de distinguir la locura de la sensatez. El jardinero Gogarty es un borrachín sin voluntad; el comisario Slocum es un desastre al que todos engañan en la comisaría y solo el abogado Alexander Peabody mantiene la compostura en sus breves apariciones.

22 El desarrollo de la acción se plantea como un proceso iniciático de David, en el que experimenta una evolución personal y espiritual típica en el cine clásico.

${ }^{23}$ Susan adopta un papel reservado habitualmente para el hombre, es la parte de la pareja más agresiva sexualmente y todas sus acciones giran en torno a un único objetivo: conseguir al hombre que desea.

${ }^{24}$ El final feliz del filme lo es solo en parte, puesto que poseen una doble lectura que enriquece profundamente la cinta dejando un sabor agridulce en el espectador porque hay estados emocionales que quedan a medio resolver o están resueltos, pero son de una moralidad un poco difusa: hay en ellos cierta renuncia por parte de los personajes principales.

${ }^{25}$ Sobre este tema se ha escrito mucho y existen diversas opiniones. Unos insisten en afirmar esta idea mientras que otros resaltan las razones por las que opinan todo lo contrario. Méndez-Leite niega los signos de misoginia: "La misoginia de Hawks es absolutamente inventada por los críticos misóginos. Las características de los personajes femeninos que inventa determinan en cada caso su opinión sobre las mujeres". MÉNDEZ-LEITE, 1975, p. 21. Robin Wood, en su estudio crítico sobre la obra de Hawks, argumenta que la presencia femenina siempre está ahí, implícita o explícitamente de un modo anómalo y amenazador. WOOD, Robin, 2006, p. 179. Perales señala que "La agresividad femenina es una amenaza para los valores masculinos que siempre han prevalecido, y aunque Hawks muestra sus efectos habitualmente en forma de comedias disparatadas, la tragedia que supone para la concepción machista es un tropiezo que acabará en un sometimiento incondicional hacia ella". PERALES, Francisco, 2005, p. 75. Tomás Fernández opina que no debe verse en ello un discurso misógino, sino más bien una suerte de ridiculización de los atributos tradicionalmente atribuidos a los varones (poder, autoridad, fuerza, capacidad organizativa), los cuales se derrumban apenas chocan de frente con una presencia femenina. FERNÁNDEZ, Tomás, 2013, p. 43. 
trama de La fiera de mi niña se articula como un proceso de caza del hombre por parte de una mujer emprendedora, caprichosa, segura de sí misma y decidida a salirse con la suya por todos los medios. Bajo su aparente irracionalidad, Susan, esconde una capacidad para seducir, y manejar a un hombre que pierde su voluntad ante la caprichosa y alocada Susan. En este aspecto, La fiera de mi niña sigue las convenciones de las screwball comedies, un género caracterizado esencialmente por incluir en sus argumentos féminas fuertes e independientes que dominaban, aparentemente sin esfuerzo, sus relaciones con los hombres que se atravesaban en su vida, llevando además la iniciativa en el terreno de la conquista. En un principio asistimos a lo que, visto bajo la perspectiva de su desconcertado protagonista, en realidad es una verdadera tragedia, una deconstrucción en toda regla de los arquetipos tradicionales masculino-femenino de la época. Tal planteamiento podría parecer progresista, pero en realidad, las screwball comedies no atacaban tanto como pudiera parecer las instituciones más tradicionales de esquema social firmemente anclado en el machismo y el paternalismo, como el matrimonio, ni el papel de la mujer en las mismas, ya que en el desenlace de sus argumentos, generalmente estas mujeres enérgicas, independientes, y en cierto modo dominadoras del varón, acababan formando pareja con el mismo, lo cual conduce a los límites marcados por la sociedad patriarcal.

Es fundamental realizar un contraste de los personajes femeninos de La fiera de mi niña, para entender la verdadera naturaleza del papel de la mujer en este filme. Alice Swallow, cuyo apellido se traduce como engullir o tragar, es un referente directo al mito de la vagina dentata, es la negación del sexo, la alegría y el impulso natural. ${ }^{26}$ Alice se muestra como una mujer que ha escogido priorizar su vida laboral antes que la familiar, este hecho su- pondría una verdadera liberación de la mujer en esa época, sin embargo, se la presenta como una mujer frígida y castradora, en una caricatura mal entendida de la libertad personal. En el otro término, Susan se muestra como una mujer cuya única meta es "cazar" a un hombre, empleando en ello múltiples argucias hasta lograr su objetivo, de este modo, Alice la mujer "liberada" es castigada y Susan, la "rebelde", acaba asumiendo el destino de toda mujer en una sociedad patriarcal, el matrimonio. De este modo, la supuesta inversión de roles, la dominación del varón por la mujer queda revertida en las secuencias finales, donde se culmina la evolución de David.

La presentación de la mujer como fuente de perdición para los hombres, es un elemento que permite descubrir los valores patriarcales que subyacen bajo las representaciones cinematográficas. ${ }^{27}$ La fiera de mi niña presenta a Susan Vance como sujeto activo de la trama, encarna a estas mujeres fuertes y dinámicas, propias de las screwball comedies y tan del gusto de Howard Hawks, decididas a conseguir sus propósitos, un propósito que no tiene otra finalidad que el matrimonio. Esta inversión de los sexos tan característica en la filmografia de Hawks, ofrece una inversión humorística del "orden natural", sin embargo y bajo esa pátina cómica, oculta una advertencia sobre este tipo de mujeres, que abandonan la sumisión del control masculino convirtiéndose en la perdición de los hombres. Obsérvese si no el auténtico calvario que soporta David, la angustiosa hora y veinte minutos que sufre el espectador y la espectadora focalizados $^{28}$ en David, bajo la influencia de las artimañas de Susan, hasta que a falta de 10 minutos para el final, David, el hombre, reestablece "el orden natural" al asumir el control de la acción con su enfrentamiento al leopardo asesino. ${ }^{29}$ Podríamos argumentar que la vida junto a Susan siempre será

\footnotetext{
${ }^{26}$ La vagina con dientes (Vagina dentata) es un mito universal que se encuentra en varias tradiciones culturales: americanas, orientales y africanas. La imagen de la vagina dentada está vinculada, primordialmente, al mito del origen femenino, donde una mujer o un grupo de mujeres surgen del cielo y "los hombres tienen que despojarlas de sus vaginas dentadas para que no sean impenetrables". STRAUSS, Lévi, 1972, p. 167. En las distintas variaciones del mito la lucha entre los sexos se dirime en torno a la posibilidad masculina de penetración frente el riesgo de castración.

27 El análisis detallado de estas comedias, siguiendo un método de trabajo deconstructivo, que desmonta las lecturas tradicionales de estos textos fílmicos, permite "hacer visible lo invisible" cuestionado la lectura patriarcal dominante. De este modo pretendemos poner de manifiesto el carácter manipulador y subjetivo de los significados construidos en estos textos especialmente en la construcción artificial y tendenciosa de los roles de género y en las relaciones que se establecen entre hombres y mujeres. A este respecto, señala Annette Kuhn que hacer visible lo invisible es una actividad analítica que puede ejercerse a distintos niveles, siendo su objetivo principal el propio texto de la película. KUHN, Annette, 1991, p. 87.

28 Pilar Aguilar señala la importancia de la identificación como condicionante activo del modo de percibir el relato que se nos cuenta puesto que actúa sobre nuestro distanciamiento y nuestra emotividad. AGUILAR, Pilar, 1996, p. 182-186.

${ }^{29}$ El protagonista principal de La fiera de mi niña es David, por ello la focalización de la información de la historia tiene lugar básicamente a través de su personaje logrando así la identificación que persigue el cine clásico entre el espectador y el personaje protagonista. Esta identificación del protagonista con el espectador queda en suspenso, en momentos puntuales de la película, generando la misma angustia e incertidumbre que al protagonista y se concentran en las secuencias que se desarrollan
} 
mejor que al lado de la señorita Swallow, pero ya señalamos que el personaje de Alice Swallow aporta multiples connotaciones negativas, que se asocian no ya con la libertad de la mujer a escojer sobre su vida, sino con un ser egoista que privilegia su vida personal y laboral sobre su papel de esposa y madre. De este modo y como comentábamos anteriormente, La fiera de mi niña, desde la perspectiva androcéntrica a la que nos aboca, ofrece un final amargo que advierte del error que se comete al permitir la inversión del "orden natural". En este aspecto, la screwball comedy parecía aceptar la posibilidad de un nuevo tipo de relación sexual entre hombres y mujeres, pero en realidad este tipo de relación se veía como síntoma de una crisis que la sociedad no podía asimilar. Y de este modo, los finales revertían invariablemente a modelos tradicionales.

La fiera de mi niña tuvo una fría acogida en su estreno el 18 de febrero de 1938. A pesar de que la película era una comedia eficaz, con todos los elementos propios de las screwball comedies, no consiguió el éxito esperado y el público le volvió la espalda en la taquilla. Este poco rendimiento en lo que a recaudación se refiere llevó al presidente de la Asociación de Salas de Cine de los Estados
Unidos, Harry Brandt, a denominar a Katharine Hepburn "veneno para la taquilla". Hepburn encabezaba una lista en la que también figuraban los nombres de Mae West, Joan Crawford, Marlene Dietrich, y hasta Greta Garbo. Como apunta Bonet, quizá no fuera ajeno al hecho de que esas actrices hubieran personificado, en la pantalla y fuera de ella, personajes de mujeres independientes, liberadas y que solían llevar la iniciativa, sin dejarse domesticar por el varón. "Tal interpretación es absolutamente verosímil porque, en contrapartida, en la relación de actrices más populares y taquilleras figuraban los nombres de Shirley Temple, Deanna Durbin y Ginger Rogers, cuyas películas se ajustaban más a la ortodoxia imperante". ${ }^{30}$ Estas críticas negativas y la escasa promoción que realizó la RKO fueron un lastre para la cinta que, tras el fracaso inicial, cayó en el olvido. ${ }^{31}$

\section{Influencias y legado}

Entre las innumerables influencias y sugerencias que ha provocado La fiera de mi niña en la historia del cine, destacan dos películas Su juego Favorito y ¿Qué me pasa doctor? (What's Up, Doc, Peter Bogdanovich, 1972). ${ }^{32}$ La primera, Su juego favorito, por ser obra del propio Hawks, que no realizó

en la casa de campo: mientras David se ducha, Susan le quita la ropa y la manda al pueblo, el espectador sabe que David no podrá vestirse cuando salga de la ducha, y sabe los motivos por los que Susan ha actuado así: con la clara intención de retrasar o incluso anular su boda con Alice. A continuación, se produce otra separación entre el espectador y el protagonista cuando George roba la clavícula intercostal que estaba sobre la cama. En esta ocasión tanto David como Susan son ajenos a lo ocurrido, hasta que lo deducen: " $i$ El perro! ¿No lo ves claro? Perro hueso, hueso perro". En la misma secuencia, se produce otra omisión de información al protagonista que resultará relevante para los hechos posteriores; se trata de la nueva identidad de David, que pasa a ser el señor Hueso, experto cazador. Susan idea esta nueva personalidad a "espaldas" de David, que ajeno a ella continúa buscando la clavícula intercostal. En esta ocasión, el espectador es consciente de la nueva identidad, pero no de la confusión que se origina de esta farsa, siendo esta una de las características principales de la screwball comedy, es decir, la sucesión de malentendidos que se derivan de las falsas identidades y que provocan situaciones confusas entre los protagonistas e hilaridad entre los espectadores. Por último, cabe destacar una falta de información que incluye a prácticamente todos los personajes: la aparición del leopardo asesino. Un hecho del que es participe el espectador, pero al que son ajenos los protagonistas hasta el desenlace del filme.

30 BONET, Lluis, 2004, p. 70.

31 El rodaje finalizó el 6 de enero de 1938, con un presupuesto de 1.073 .000 dólares. RKO había gastado un millón de dolares de presupuesto en la película y acabó perdiendo 365.000 dólares con ella tras su estreno, que estuvo a punto de no producirse porque la compañía estaba dispuesta a sepultar el filme como un costoso error antes de gastar el dinero necesario para completar su montaje y pagar la promoción. Finalmente, Howard Hughes adquirió los derechos de la película para revendérselos a la cadena de exhibición Loew, consiguiendo de esta manera que pudiera estrenarse y llegar al público. BONET, Lluis, 2004, p. 70.

${ }_{32}$ Al margen de estas dos revisiones del filme, La fiera de mi niña ha servido de inspiración y modelo a numerosas comedias románticas que retoman la imagen de la mujer como "fuente de problemas para el hombre". Descalzos en el parque (Barefoot in the Park, Gene Sack, 1967) desarrolla los vaivenes en la relación de dos recién casados de caracteres muy diferentes, Paul (Robert Redford), un abogado reflexivo y predecible y Corie (Jane Fonda) su impredecible y caótica esposa que entiende la vida como constante fuente de diversión. Este choque de caracteres provocará que atraviesen diferentes fases de amor-odio, hasta lograr un equilibrio que pasa por un proceso de liberación para Paul que le permitirá aflorar actitudes reprimidas, y un punto de reflexión en la caótica forma de vida de Corie que se tornará más pausada. En el siglo XXI, la modelo continua vigente, tal y como podemos apreciar en Y entonces llegó ella (Along Came Polly, John Hamburg, 2004), que tiene como protagonista a Reuben (Ben Stiller) asesor de riesgos de una gran empresa que siente pánico por cualquier actividad que suponga riesgo y aventura. Abandonado en su Luna de Miel por su mujer, que lo cambia por un monitor de submarinismo, retorna a su monótona rutina, que se ve trastocada con la aparición de Polly (Jennifer Aniston) que dará un vuelco a su vida introduciendo la locura y el desenfreno junto a la inestimable ayuda de su mascota, un hurón con el que Reuben se verá obligado a convivir, a pesar de su inicial animadversión hacia él. Si Polly continua el modelo establecido por Katharine Hepburn en su recreación de 


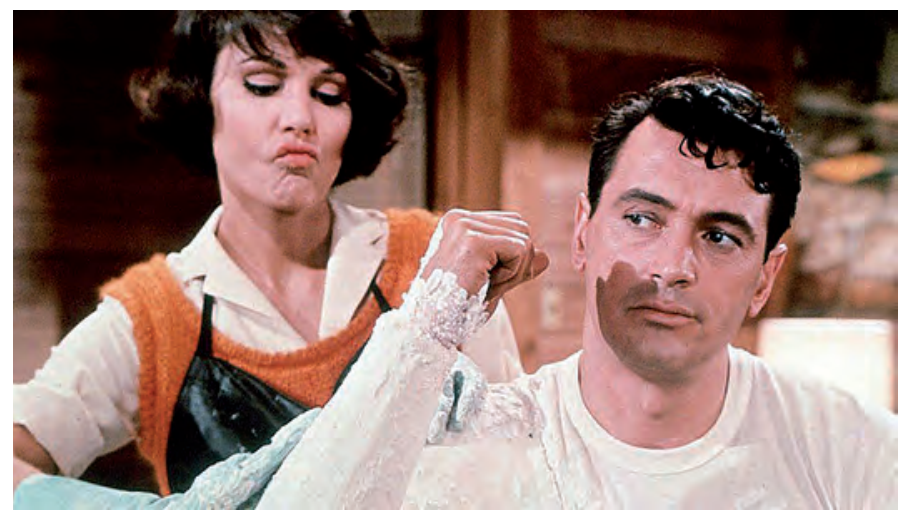

Fig. 4. Fotograma de la película Su juego favorito.

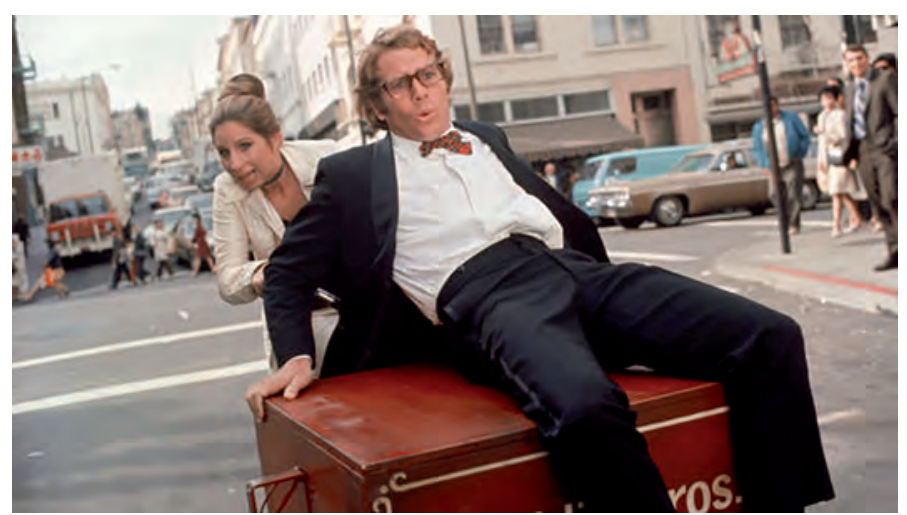

Fig. 5. Fotograma de la película ¿Qué me pasa doctor? una nueva versión del filme, pero sí retomó la idea del hombre arrastrado a su pesar a través de una tormenta de equívocos y situaciones embarazosas, por una mujer que trata de atraparlo sin confesarlo nunca y que pasa de resultar odiosa a ser amada. En este caso era Rogers (Rock Hudson) el que se hacía pasar por un deportivo experto en pesca y en realidad resultaba ser un impostor incapaz de sobrevivir al aire libre, hasta que Abigail (Paula Prentiss) le zambulle en mil humillaciones para pasar por el aprendizaje que le saca de su vida cuadriculada, la pérdida y la recuperación de su dignidad. ${ }^{33}$ El ritmo era más pausado que en La fiera de mi niña y el personaje femenino tenía una derivación a través de su amiga "Easy" (Maria Perschy), pero Hawks se reservó algunas referencias directas a $L a$ fiera de mi niña, como el encuentro entre la pareja protagonista en un aparcamiento con una discusión por sus coches, el vestido roto de ella o la utilización de la frase sobre los impulsos amorosos del hombre expresados con actitudes violentas. ${ }^{34}$

Hawks siempre defendió este juego de correspondencias:

Si hacemos una película que es un éxito, que gusta a la gente, nos sentimos inclinados a querer hacer una versión diferente de la misma película. Y si un director tiene una historia que le gusta y la cuenta, muy a menudo ve la película y dice, "Podría hacerla mejor si la volviera a hacer", así que yo la volví a hacer. Seguiré haciéndolas, de formas diferentes. ${ }^{35}$

En Su juego favorito, Abigail se presenta también como una mujer agresiva que domina todas las circunstancias y que está convencida de poder some-

Susan Vance, con original mascota incluida, la protagonista de la película de animación The Croods (Chris Sanders, Kirk DeMicco, 2013), lo aborda magistralmente. Eep en una recreación de la pelirroja atrevida y descarada que persigue incansable a un escurridizo y sabio "científico", Guy, que trae consigo el gran avance de la humanidad, el fuego, y que sin embargo, se ve sometido, muy a su pesar, a una serie de situaciones embarazosas y accidentes que terminarán con su resignada unión al clan de los Croods.

${ }^{33}$ Abigail y Easy son unas expertas deportistas que se manejan con gran soltura en ambientes agrestes al contrario que Rogers, totalmente inexperto en este tema.

${ }^{34}$ Hawks no dudó en repetir la escena en Su juego favorito, esta vez interpretada por Rock Hudson y Maria Perschy aunque con menor soltura. Robin Wood apunta incluso cierta crueldad por parte del director al hacerles repetir la famosa escena del "night Club". WOOD, Robin, 2006, p. 134. Hawks solo figura como colaborador en los guiones de cuatro películas (todas anteriores a la década de los treinta) sin embargo siempre cooperó activamente con los escritores que trabajaron para él; supo valorar las estructuras de sus historias, así como los diálogos de los personajes ejerciendo un férreo control en la etapa de escritura. Su intervención como co-guionista en sus obras es obvia, sobre todo cuando vemos como hay momentos que se repiten sucesivamente en sus películas y que no pertenecen a los mismos guionistas: en La fiera de mi niña (1938, guion de Dudley Nichols y Hagar Wilde), Me siento rejuvenecer (1952; guion de Ben Hecht, I.A.L Diamond y Charles Lederer) y Su juego favorito (1964; guion de John Fenton Murray y Steve McNeil) se reproducen una escena, en la que la protagonista, por diferentes razones, deja al descubierto su trasero y el protagonista masculino le ayuda en las tres ocasiones a ocultar su vergüenza; en $L a$ Fiera de mi niña y Su juego favorito se desarrolla además, de forma muy similar, un enfrentamiento verbal entre hombre y mujer en un aparcamiento. Sobre esta contradicción entre las películas en las que aparece acreditado y en las que realmente participa el propio Hawks da una explicación: "Si apareciera más a menudo, no conseguiría que escritores tan buenos trabajaran para mí" (Because if I did, I couldn't get such good writers to work with me"). McBRIDE Joseph, 1982, p. 30.

35 "If we make a picture that's a top-biller, that the people like, we're inclined to want to do a different version of the same picture. And if a director has a story that he likes and he tells it, very often he looks al the picture and says, 'I could do that better if I did it again', so l'd do it again. I'll keep on doing them, in a different way". McBRIDE, Joseph, 1982, p. 133. 
ter al hombre en un mundo que es de las mujeres, sin embargo, en esta nueva propuesta se operan algunos cambios que resulta útil resaltar. Separadas por más de veinticinco años, La fiera de mi Niña (1938) y Su juego favorito (1964) ofrecen un interesante estudio para comparar cómo Hawks adapta su habitual inversión de estereotipos al paso del tiempo y a la evolución del papel de la mujer en la sociedad. La agresividad sexual de Susan a finales de la década de los 30 era algo inusitado, pero esa misma agresividad sexual es muy inferior en Abigail, que se emplea de una forma más sutil a la hora de conquistar a Roger. Hawks recicla esta agresividad femenina y da un vuelco en el estereotipo del comportamiento sexual, hace a Abigail tímida, dubitativa y menos descarada que otras mujeres hawksianas como Susan. Y sin embargo Abigail sí es una mujer muy resuelta y agresiva en sus proyectos profesionales, solo hay que ver cómo se desenvuelve en el primer tercio de la película, llegando sin rubor al chantaje, para conseguir su objetivo: lograr la participación de Roger en un evento deportivo que lo pondrá bajo su dominio.

Años más tarde, Peter Bogdanovich haría un homenaje con otra remodelación de La fiera de mi niña, ¿Qué me pasa doctor? (What's Up, Doc, 1972). Bogdanovich, apasionado por Hawks, no resistió la tentación de utilizar los hallazgos de su maestro en un intento de revitalizar las screwball comedies. De nuevo, el científico despistado y encorsetado, Howard Bannister (que en lugar de tener entre manos una clavícula intercostal habla continuamente de rocas ígneas) interpretado por Ryan O'Neal, sucumbe ante la imparable Judy Maxwell (Barbra Streisand) que le saca de su aburrida vida, junto a su prometida Eunice Burns (Madeline Karns), y le despierta los instintos adormecidos. Bogdanovich cambia de argumento, pero recupera la batalla entre los protagonistas, en una divertida inversión de roles, las referencias al slapstick e incluso el vestido rasgado. Hawks, consideraba que ¿Qué me pasa, doctor? era divertida; todos los golpes visuales eran endiabladamente buenos. No tuvo ningún problema al verse copiado: "Le dije a Peter, 'Cometiste un error diciéndoles de dónde la habías copiado'. Yo no les dije de dónde la había copiado yo". ${ }^{36}$

Fue Bogdanovich, en el ciclo de Hawks que organizó en el MOMA neoyorquino y en el correspon- diente libro que editó, quién inició la recuperación de La fiera de mi niña y puso las primeras anotaciones para su reconsideración. ${ }^{37}$ La película se volvió a exhibir en enero de 1961, tras permanecer veinte años apartada de las salas. En la misma obtuvo un éxito arrollador y toda una nueva generación de cinéfilos la adoptó como una de las obras maestras de la comedia clásica norteamericana, convirtiéndose en uno de sus títulos más paradigmáticos, tanto para la comprensión de toda la obra de Howard Hawks y de sus estrellas principales, Katharine Hepburn y Cary Grant, como para considerar el desarrollo de toda la tradición de la guerra de los sexos en el cine de Hollywood.

\section{Bibliografía}

AGUILAR, Pilar. Manual del espectador inteligente. Madrid: Editorial Fundamentos, 1996.

BOGDANOVICH, Peter. The Cinema of Howard Hawks. Nueva York: Film Library of The Museum of Modern Art of New York, 1962.

BOGDANOVICH, Peter. El director es la estrella, Vols II. Madrid: T\&B editores, 2008.

BONET, Lluis. Cary Grant. El capricho de las damas. Madrid: T\&B editores, 2004.

CARR, Jay. The A List; The National Society of Film Critics 100 Essential Films. Boston: Da capo Press, 2002.

CAVELL, Stanley. La búsqueda de la felicidad. La comedia de enredo matrimonial en Hollywood. Barcelona: Paidós, 1999.

DELEYTO, Celestino. "La comedia y la risa en el cine: historias de amor y sexo en I Was a Male War Bride", Archivos de la filmoteca, 2001, febrero n 37, p. 165-181.

ECHART, Pablo. La comedia romántica del Hollywood de los años 30 y 40. Madrid: Cátedra, 2005.

FERNÁNDEZ, Tomás. "La comedia según Howard Hawks. El absurdo como forma de vida" Dirigido por..., junio 2013, p. 42-47.

HASKELL, Molly. From Reverence to Rape. The Treatment of Woman in the Movies. Chicago: University of Chicago Press, 1987.

KUHN, Annette. Cine de mujeres. Feminismo y cine. Madrid: Cátedra, 1991.

McBRIDE, Joseph. Hawks on Hawks. Berkeley and Los Ángeles: University of California Press, 1982.

MÉNDEZ-LEITE, Fernando (1975), "Howard Hawks", en Dirigido por..., $\mathrm{n}^{\circ} 24$, junio de 1975 , p. 7-24.

NEALE, Steve y KRUTNIK, Frank. Popular film and Television Comedy. Nueva York y Londres: Routledge, 1990.

PERALES, Francisco. Howard Hawks. Madrid: Cátedra, 2005.

STRAUSS, Lévi. Mitológicas II. De la miel a las cenizas. México: FCE, 1972.

WOOD, Robin. Howard Hawks. Londres: British Film Institute, 1981

\footnotetext{
36 "You made a mistake in telling 'em where you stole it from. I didn't tell'em where I stole it from". McBRIDE, Joseph, 1982, p. 69

37 BOGDANOVICH, Peter, 1962.
} 